\title{
Clinical Observations Planned Time Point Number
}

National Cancer Institute

\section{Source}

National Cancer Institute. Clinical Observations Planned Time Point Number. NCI

Thesaurus. Code C119817.

The numerical identifier of a clinical observation point in time. 